\title{
Estudo cinético da obtenção de ésteres utilizando enzima lipozyme TL IM como catalisador
}

\author{
Kinetic study of the production of the aliphatic ester n-amyl octanoate \\ by direct esterification using the enzyme Lipozyme TL IM as catalyst
}

Everton SKORONSKI ${ }^{1,2 *}$, Thiago Medeiros BONETTI ${ }^{1,2}$, Jair Juarez JOÃO ${ }^{1}$, Agenor FÚRIGO JÚNIOR ${ }^{2}$

\begin{abstract}
Resumo
Nesse trabalho foi estudada a produção do éster alifático octanoato de $n$-pentila por esterificação direta usando a enzima Lipozyme TL IM como catalisador, sendo esse éster usado como aroma na indústria de alimentos. Foi verificada a influência da concentração inicial de substratos na velocidade inicial da reação, sendo esta determinada através do consumo de ácido octanoico ao longo do tempo. Modelos cinéticos clássicos descritos na literatura não se ajustaram bem aos dados experimentais. A máxima velocidade da reação foi alcançada a $40^{\circ} \mathrm{C}$. A enzima Lipozyme TL IM sofre inibição por substrato.

Palavras-chave: Lipozyme; éster; cinética.
\end{abstract}

\begin{abstract}
In this work, the production of the aliphatic ester $n$-amyl octanoate by direct esterification using the enzyme Lipozyme TL IM as catalyst was studied. The influence of the initial concentration of the substrate on the initial rate of reaction was verified. The initial rate of the reaction was determined by the octanoic acid consumption over time. The kinetic models described in the literature did not fit to the experimental data. The maximum rate was reached at $40{ }^{\circ} \mathrm{C}$. Lipozyme TL IM was inhibited by the initial concentration of the substrate.

Keywords: Lipozyme; esters; kinetics.
\end{abstract}

\section{Introdução}

Os ésteres são importantes compostos orgânicos, obtidos por síntese química (esterificação, transesterificação ou interesterificação) ou extraídos de alguns produtos naturais, utilizando-se solvente e meio adequado (ROBERTS; CASERIO, 1997). Suas aplicações comerciais são bastante difundidas, sendo que diversos processos de obtenção industrial desses compostos, encontram-se bem sedimentados no setor produtivo.

A síntese de ésteres, de um modo geral, envolve reações que possuem velocidades bastante baixas, se forem realizadas sem a utilização de um catalisador adequado (ABBAS; COMEAU, 2003; CHANG; SHAW; SHIEH, 2003). Assim, é necessário o emprego de catalisadores, sendo geralmente utilizados ácidos como o sulfúrico e o clorídrico ou bases como o hidróxido de sódio ou o hidróxido de potássio (ROBERTS; CASERIO, 1997). Por tratar-se de uma catálise homogênea, a purificação dos produtos da reação acaba tornando o processo oneroso, além de não gerar produtos com alto grau de pureza (COSTA et al., 2003; FERREIRA-DIAS; FONSECA, 1995; JESUS; SILVA, 2003).

Estudos recentes vêm demonstrando que as enzimas, em particular as lipases, podem ser aplicadas na síntese de diversos ésteres (JESUS; SILVA, 2003; GANDHI, 1997; JOÃO; ZANELLA, 2000; DIAS et al., 1991; ŞEKEROĞLU; FADILOĞLU; İBANOĞLU, 2004; VIEIRA; SILVA; LANGONE,
2006; OLIVEIRA et al., 2004). Os processos que utilizam enzimas como catalisador podem ser conduzidos em condições muito mais brandas de pressão, temperatura e $\mathrm{pH}$ quando comparados aos processos que utilizam catalisadores inorgânicos (DALLAVECHIA et al., 2004; SCHMID; VERGER, 1998).

Além das vantagens operacionais proporcionadas pelo uso de enzimas na síntese de ésteres, características atrativas para a venda desses compostos também são observadas. Um exemplo está associado à produção de aromas. Se este for sintetizado por via biológica, por fermentação ou utilizando enzima como catalisador, ele é considerado natural, tornando o composto mais atrativo comercialmente (ABBAS; COMEAU, 2003; GABELAN, 1994; FABER, 2000; CHANG et al., 2005).

Embora diversos trabalhos na literatura descrevam a síntese de ésteres a partir de enzimas, um detalhamento maior sob o ponto de vista de cinética química deve ser mais explorado, gerando dados para a construção de reatores em escala real (CONNORS, 1990; SHULER; KERGI, 1992, REHM et al., 1995; MOSER, 1988).

Neste trabalho foi verificado o rendimento da reação de esterificação do ácido octanoico com diversos alcoóis alifáticos, catalisada pela enzima comercial Lipozyme TL IM, produzida e comercializada na forma imobilizada pela Novozymes, conforme

Recebido para publicação em 12/9/2008

Aceito para publicação em 8/7/2009 (003705)

${ }^{1}$ Grupo de Pesquisas em Catálise Enzimática e Síntese Orgânica, Universidade do Sul de Santa Catarina - UNISUL, Av. José Acácio Moreira, n. 787, CEP 88704-900,

Tubarão-SC,Brasil,E-mail: everton.skoronski@unisul.br

2 Departamento de Engenharia Química e Engenharia de Alimentos, Universidade Federal de Santa Catarina - UFSC, Campus Universitário Trindade, CEP 88040-900, Florianópolis - SC, Brasil

${ }^{*}$ A quem a correspondência deve ser enviada 
trabalhos realizados anteriormente (JOÃO; ZANELLA, 2000). Além disso, foram coletados dados experimentais referentes à velocidade da reação, variando a concentração inicial de reagentes, sendo que, após essa etapa, foram ajustados modelos matemáticos encontrados na literatura aos dados experimentais obtidos. A escolha dos compostos, que foram utilizados como substratos padrão para este estudo, esta relacionada ao melhor rendimento obtido entre os diversos ésteres alifáticos, sendo a síntese conduzida pela mesma enzima em questão.

\section{Material e métodos}

\subsection{Reagentes e soluções}

Os substratos utilizados para esse estudo foram etanol, propanol, $n$-butanol, $n$-pentanol, $n$-hexanol, $n$-octanol, $n$-decanol, e ácido octanoico (Merck). O solvente aplicado nas sínteses foi o $n$-hexano (Merck). Para as análises, foi utilizado $\mathrm{KOH}$ (Vetec) dissolvido em etanol (Nuclear). Os ensaios de infravermelho foram realizados com pastilhas de $\mathrm{KBr}$ (Fluka). A enzima utilizada foi a Lipozyme TL IM fornecida pela Novozymes.

\subsection{Definição do substrato padrão}

A definição dos substratos padrão que seriam aplicados aos estudos cinéticos foi baseada na análise das conversões observadas após 48 horas de síntese dos ésteres do ácido octanoico com diferentes alcoóis alifáticos (etanol, propanol, $n$-butanol, $n$-pentanol, $n$-hexanol, $n$-octanol e $n$-decanol). As reações foram conduzidas em erlenmeyers de $125 \mathrm{~mL}$, a $30^{\circ} \mathrm{C}$, em banho-maria tipo DUBNOFF sob agitação constante de $70 \mathrm{rpm}$. Os substratos foram adicionados em razão molar de 1:1, em concentração de $0,4 \mathrm{~mol} \cdot \mathrm{L}^{-1}$. O volume da reação foi de $50 \mathrm{~mL}$. Não foi adicionada água ao meio reacional. A enzima utilizada foi a Lipozyme TL IM, aplicada na razão mássica de $10 \%$ em relação à massa total de substratos. A conversão foi definida em função da quantidade de ácido octanoico consumido durante a reação. Para realização dos ensaios cinéticos, foi utilizado o ácido octanoico e o álcool que gerou o maior rendimento na reação de esterificação.

\subsection{Determinação das cinéticas de esterificação}

A síntese do éster foi realizada em diferentes condições de concentração de substrato $\left(0,1\right.$ a 0,95 mol. $\left.\mathrm{L}^{-1}\right)$ e temperatura ( 30 , 40 e $50^{\circ} \mathrm{C}$ ), dissolvidos em $n$-hexano. Os substratos utilizados foram ácido octanoico e $n$-pentanol, definidos após realização do ensaio descrito anteriormente. O octanoato de $n$-pentila é um éster artificial que compõe a mistura de compostos responsáveis pelo aroma de manga (MACLEOD; SNYDER, 1985). Foram mantidos parâmetros reacionais constantes, como a razão estequiométrica de $n$-pentanol / ácido octanoico, fixada em 1:1, a quantidade do sistema enzima/suporte (Lipozyme TL IM) adicionada no meio, que foi de $10 \%(\mathrm{~m} / \mathrm{m})$ em relação à massa total de substratos, e sem adição de água ao meio. A partir disso, a reação foi conduzida por 40 minutos em banho-maria sob agitação constante de aproximadamente $70 \mathrm{rpm}$. Os reagentes e solvente utilizados nas reações foram previamente secos em peneira molecular para evitar a adição de água ao meio reacional.

\subsection{Análise de rendimento das reações}

A determinação da quantidade de ácido octanoico na reação foi feita por titulação volumétrica do tipo ácido-base, sendo um indicativo da conversão do ácido em éster ao longo do tempo. Embora a reação ocorra com dois substratos, esses eram consumidos com a mesma velocidade pelo fato de a reação ocorrer na razão molar de 1:1, permitindo a concentração de ácido octanoico representar a concentração de substratos.

Para as análises de titulação, foram utilizadas duas soluções de $\mathrm{KOH}$, dissolvidas em etanol (COSTA NETO, 2002; CASTRO; PAULA; BARBOZA, 2005). Alíquotas de $200 \mu \mathrm{L}$ foram retiradas do meio reacional a cada 10 minutos para análise e diluídas para $2 \mathrm{~mL}$ com solução alcoólica $96^{\circ} \mathrm{GL}$.

Com os dados obtidos, foram construídos gráficos que relacionam a concentração de ácido octanoico restante na solução em determinado instante.

Para determinar qualitativamente a geração do éster no meio reacional, foram retiradas alíquotas do meio e realizadas análises de Espectroscopia de Infravermelho com Transformada de Fourier (FTIR). Para a realização dessa análise, foram utilizadas pastilhas de $\mathrm{KBr}$.

\subsection{Analise cinética das reações}

Para determinar a velocidade inicial da reação para cada concentração inicial de substratos, foram realizados ajustes lineares com o objetivo de descrever matematicamente o consumo de ácido octanoico durante os instantes iniciais da reação. O coeficiente angular da reta obtida representa a velocidade média da reação durante o intervalo de tempo considerado.

Para descrever matematicamente a influência da concentração inicial dos substratos na velocidade inicial da reação, foram utilizados modelos matemáticos de inibição por substrato descritos na literatura.

Os dois modelos utilizados foram:

- Modelo clássico de inibição (SCHIMIDELL et al., 2001):

$$
v=V_{m} \frac{C_{s}}{C_{s}+K_{s}+\frac{C_{s}^{2}}{K_{i}}}
$$

- Modelo proposto por Wu et al. (1988) para cinética de fermentação:

$$
v=V_{m} \frac{1}{1+\frac{K_{s}}{C_{s}}+\left(\frac{C_{s}}{K_{i}}\right)^{n}}
$$

onde: $v=$ velocidade de formação do produto (mol. $\mathrm{L}^{-1} / \mathrm{minuto}$ ); $V_{m}=$ parâmetro da equação (mol. $\mathrm{L}^{-1} /$ mininuto); $C_{s}=$ concentração de substrato $\left(\mathrm{mol}^{-1} \mathrm{~L}^{-1}\right) ; K_{s}=$ parâmetro da equação $\left(\mathrm{mol} . \mathrm{L}^{-1}\right)$; $K_{i}=$ contante de inibição $\left(\right.$ mol.L $\left.^{-1}\right) ; n=$ parâmetro da equação. 
Para a determinação dos parâmetros, $V_{m}$, $K_{s}$ e $K_{i}$, foi utilizado o software STATISTICA ${ }^{\circledast}$ for Windows versão 5.1 da Stat Soft, na qual foi aplicado o método Hooke-Jeeves.

\section{Resultados e discussão}

As conversões obtidas para a esterificação do ácido octanoico com os diversos alcoóis alifáticos, catalisada pela enzima Lipozyme TL IM, encontram-se na Tabela 1.

Através dos resultados, pode-se observar que o maior rendimento de conversão em éster ocorre quando é utilizado o n-pentanol como álcool. Para substratos de cadeia mais longa, observamos uma menor conversão, provavelmente provocada pela baixa afinidade da enzima com estes substratos de cadeia longa. Para alcoóis de cadeia curta, a reação também apresenta um baixo rendimento quando comparado com alcoóis como $n$-butanol, $n$-pentanol e $n$-hexanol. Essa observação pode estar ligada à alta polaridade do etanol e propanol quando comparada aos demais alcoóis.

Diante dos resultados obtidos, foi selecionada a reação modelo de esterificação do ácido octanoico com n-pentanol, para execução dos estudos cinéticos do processo.

As Figuras de 1 a 6 apresentam a relação entre a concentração inicial dos reagentes e a velocidade inicial da reação. Nas Figuras 1, 2 e 3, temos o ajuste do modelo cinético clássico, e nas Figuras 4, 5 e 6 temos o ajuste do modelo proposto por $\mathrm{Wu}$ et al. (1988) aos dados experimentais.

Os resultados demonstram que até um determinado ponto a velocidade inicial da reação é função direta da concentração inicial dos substratos. Entretanto, para concentrações muito altas, a enzima sofre inibição pelo substrato, independentemente do valor de temperatura ao qual a reação foi conduzida. Esse fato é bastante

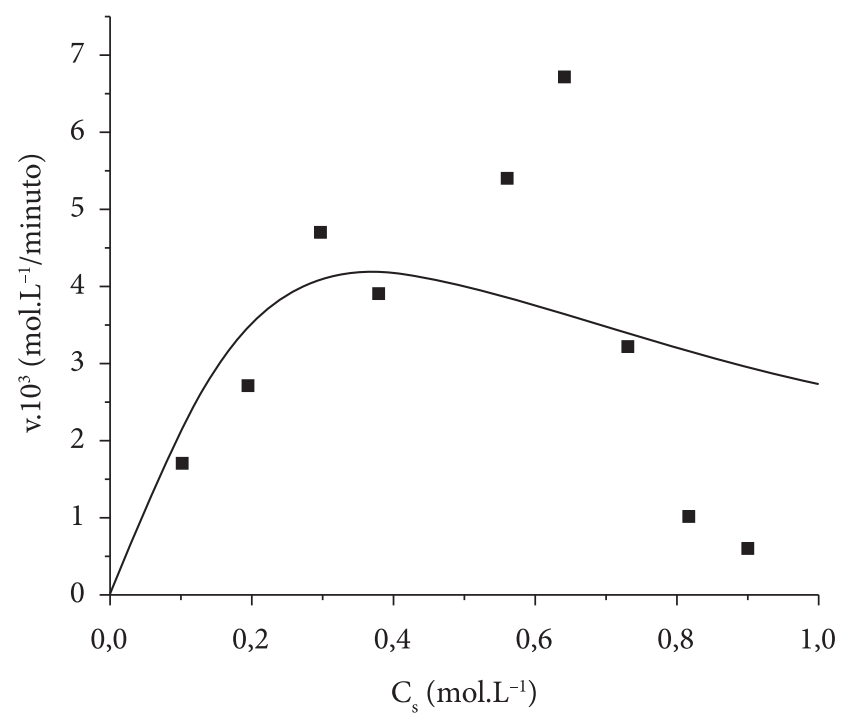

- Dados experimentais $\left(30^{\circ} \mathrm{C}\right)$ - Modelo matemático

Figura 1. Ajuste do modelo matemático clássico de inibição aos dados experimentais obtidos a partir das reações realizadas na temperatura de $30^{\circ} \mathrm{C}$. comum com lipases, quando atuam em reações em que alcoóis fazem parte dela. Pode-se perceber que a inibição ocorre para valores acima de $0,65 \mathrm{~mol} . \mathrm{L}^{-1}$. Para valores próximos a 1,00 mol. $\mathrm{L}^{-1}$, a reação é bastante lenta ou até mesmo inexistente, uma vez que não foi possível observar a formação do produto através das técnicas utilizadas, titulação volumétrica e espectroscopia de infravermelho. Com relação à velocidade máxima alcançada, o valor alcançado foi 6,7, 9,2 e 8,0 $\mathrm{mmol} . \mathrm{L}^{-1} / \mathrm{minu}$ para as temperaturas de 30,40 e $50^{\circ} \mathrm{C}$, respectivamente.

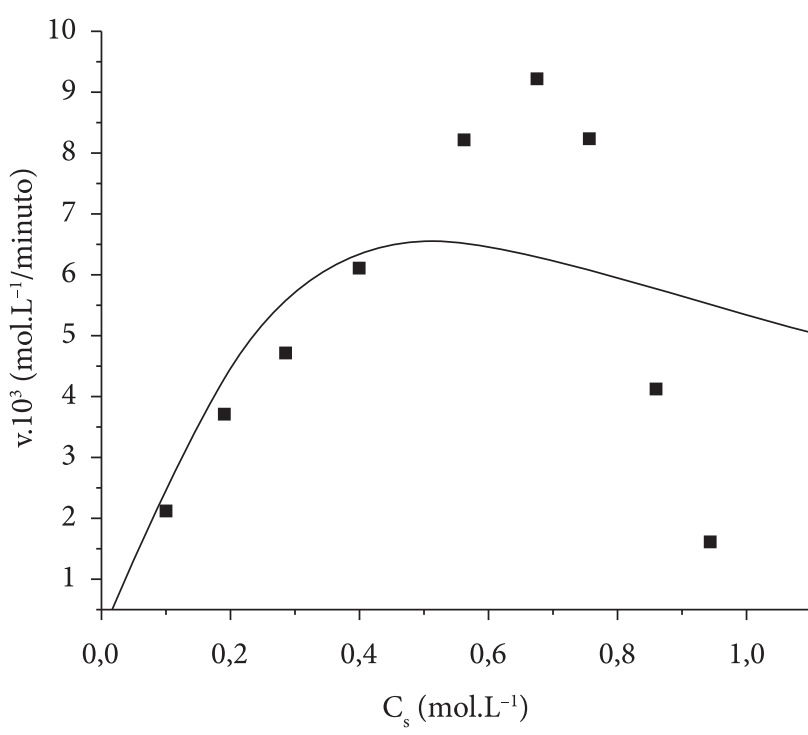

- Dados experimentais $\left(40^{\circ} \mathrm{C}\right)$ - Modelo matemático

Figura 2. Ajuste do modelo matemático clássico de inibição aos dados experimentais obtidos a partir das reações realizadas na temperatura de $40{ }^{\circ} \mathrm{C}$.

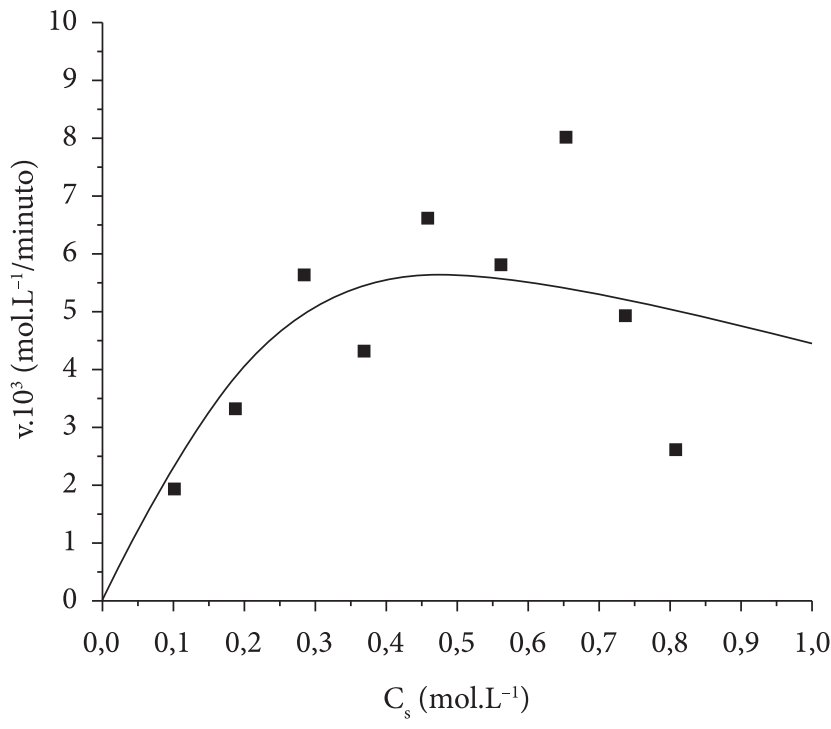

- Dados experimentais $\left(50^{\circ} \mathrm{C}\right)$ — Modelo matemático

Figura 3. Ajuste do modelo matemático clássico de inibição aos dados experimentais obtidos a partir das reações realizadas na temperatura de $50^{\circ} \mathrm{C}$. 
Além disso, é possível observar que o modelo matemático clássico utilizado não apresentou uma boa correlação com os resultados experimentais, justificados pelos baixos coeficientes de correlação $\left(R^{2}\right)$ com os dados experimentais $(0,571,0,604 \mathrm{e}$ 0,557 para as temperaturas de 30,40 e $50^{\circ} \mathrm{C}$, respectivamente). $\mathrm{O}$ aspecto da curva apresentado pelo modelo matemático leva a concluir que essa equação descreve melhor, processos em que a velocidade da reação é reduzida de maneira suave devido ao aumento da concentração inicial de substrato.

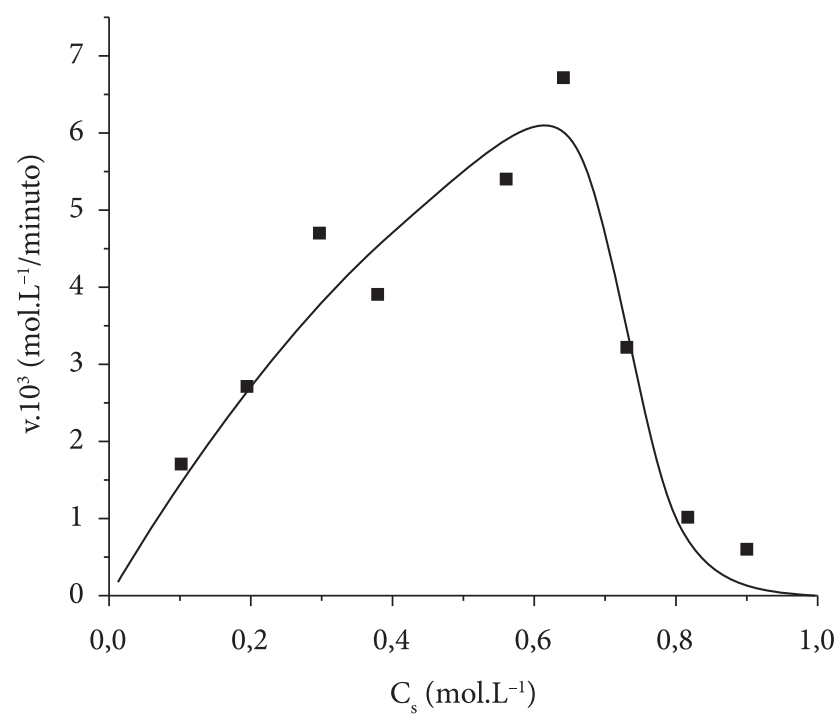

- Dados experimentais $\left(30^{\circ} \mathrm{C}\right)$ - Modelo matemático

Figura 4. Ajuste do modelo matemático proposto por Wu et al. (1988) aos dados experimentais obtidos a partir das reações realizadas na temperatura de $30^{\circ} \mathrm{C}$.

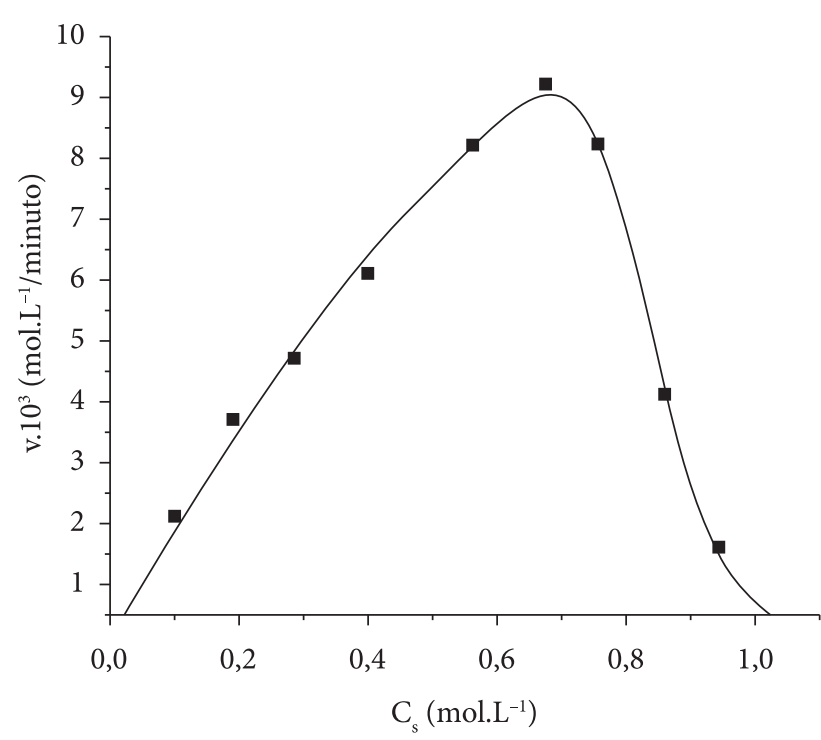

- Dados experimentais $\left(40^{\circ} \mathrm{C}\right)$ - Modelo matemático

Figura 5. Ajuste do modelo matemático proposto por Wu et al. (1988) aos dados experimentais obtidos a partir das reações realizadas na temperatura de $40^{\circ} \mathrm{C}$.
Entretanto, o modelo proposto por Wu et al. (1988) se adapta com maior sucesso aos dados experimentais quando comparado com o modelo clássico de inibição, levando em consideração os valores de coeficiente de correlação (Tabela 2).

Os valores dos parâmetros para o modelo proposto por $\mathrm{Wu}$ et al. (1988) estão ilustrados na Tabela 2.

$\mathrm{O}$ valor médio do parâmetro $\mathrm{n}$, considerando uma média aritmética entre os valores obtidos para as três temperaturas, apresentou um valor de $17,11 \pm 1,83$. A escassez de dados na literatura a respeito do significado físico desse parâmetro sugere a realização de um maior número de experimentos de forma a gerar conclusões a respeito da sua relação com o mecanismo da reação proposta.

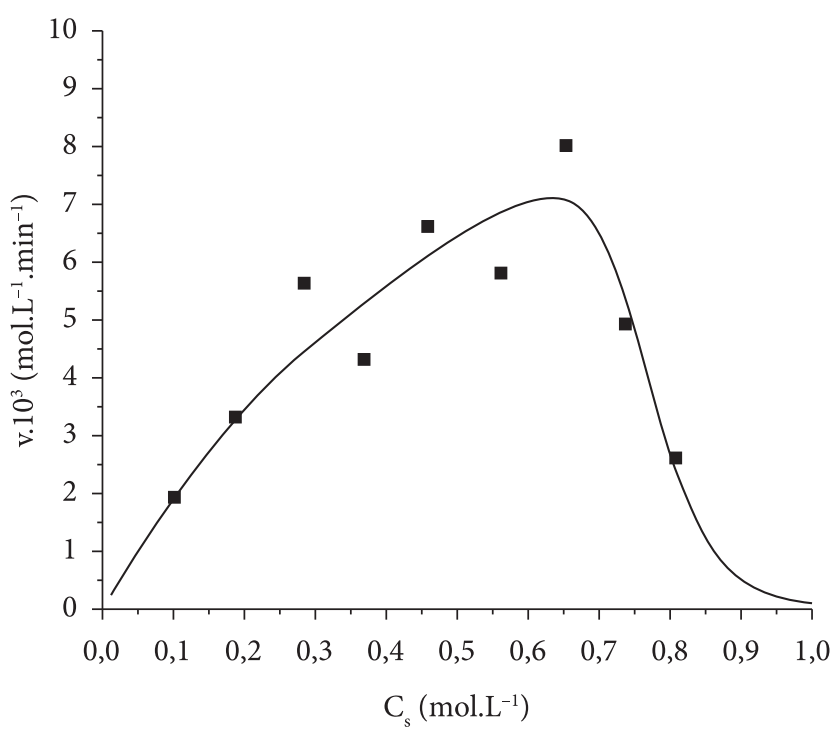

- Dados experimentais $\left(50^{\circ} \mathrm{C}\right)$ - Modelo matemático

Figura 6. Ajuste do modelo matemático proposto por Wu et al. (1988) aos dados experimentais obtidos a partir das reações realizadas na temperatura de $50{ }^{\circ} \mathrm{C}$.

Tabela 1. Conversões obtidas para a esterificação do ácido octanoico com diferentes alcoóis alifáticos. Concentração de substratos iguais a 0,4 mol. $L^{-1}$, razão molar de substratos $1: 1$, temperatura de reação igual a $30^{\circ} \mathrm{C}$, tempo de reação de 24 horas e agitação a $70 \mathrm{rpm}$ e $10 \%$ de enzimas/suporte Lipozyme TL IM em relação à massa total dos substratos.

\begin{tabular}{llc}
\hline Ácido carboxílico & Álcool & Rendimento (\%) \\
\hline Ácido octanoico & etanol & 25 \\
& $n$-propanol & 67 \\
$n$-butanol & 93 \\
& $n$-pentanol & 95 \\
& $n$-hexanol & 92 \\
& $n$-octanol & 82 \\
& $n$-decanol & 77 \\
\hline
\end{tabular}




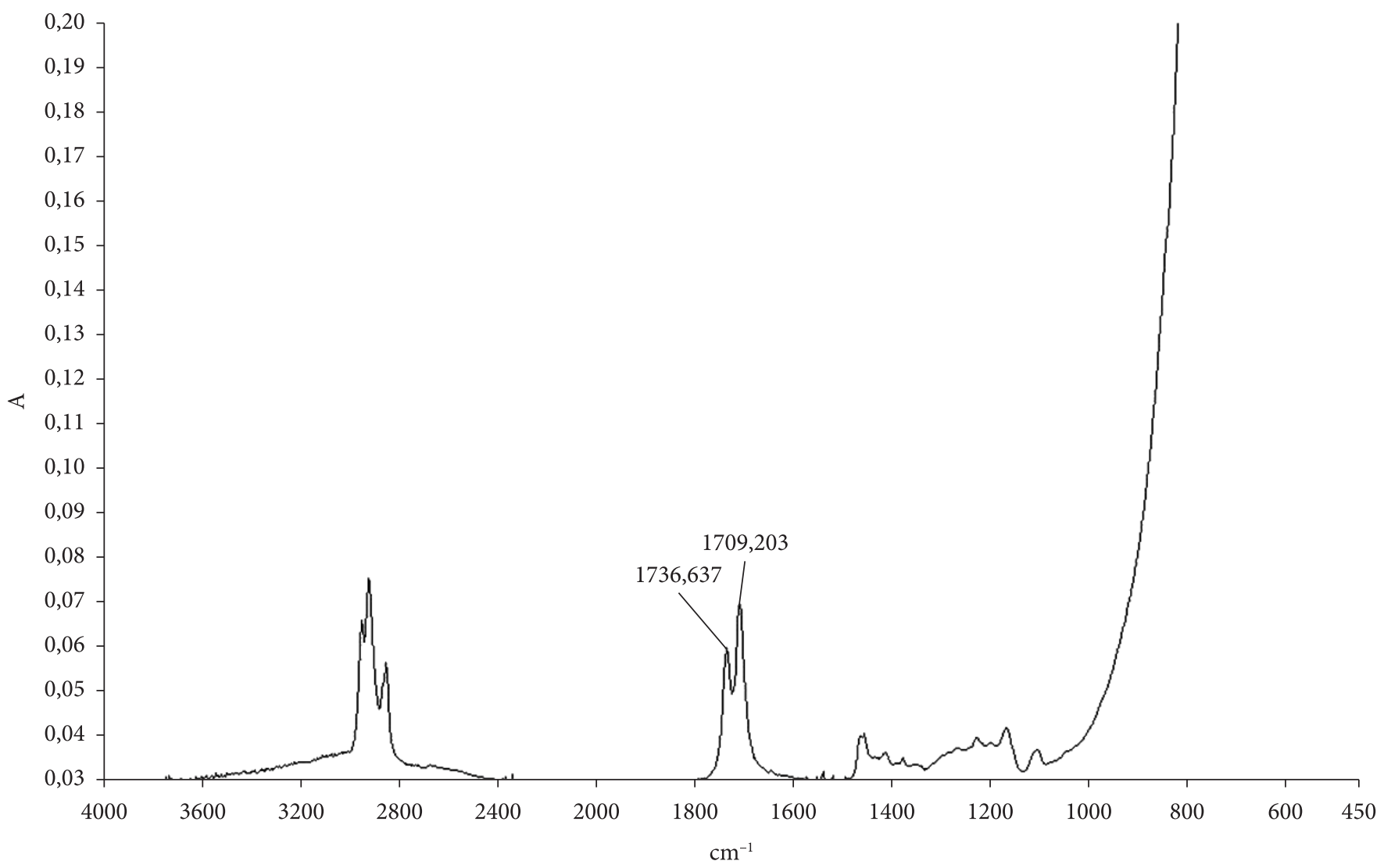

Figura 7. Espectro de infravermelho para amostra removida durante a reação.

Tabela 2. Parâmetros obtidos para o ajuste do modelo matemático proposto por $\mathrm{Wu}$ et al. (1988) aos dados experimentais obtidos. Concentrações de substratos $\left(0,1\right.$ a 0,95 mol. $\left.\mathrm{L}^{-1}\right)$ e temperaturas (30, 40 e $50^{\circ} \mathrm{C}$ ), solvente $n$-hexano e razão estequiométrica de $n$-pentanol / ácido octanoico, fixada em 1:1, a quantidade do sistema enzima/suporte (LIPOZYME TL IM) adicionada no meio foi de $10 \%(\mathrm{~m} / \mathrm{m})$ em relação à massa total de substratos, e sem adição de água ao meio

\begin{tabular}{cccccc}
\hline $\mathrm{T}$ & \multicolumn{5}{c}{ Parâmetros } \\
\cline { 2 - 6 }$\left({ }^{\circ} \mathrm{C}\right)$ & $\mathrm{V}_{\max }\left(\right.$ mol.L $\mathrm{L}^{-1} /$ minuto $)$ & $\mathrm{K}_{\mathrm{s}}\left(\mathrm{mol}_{\mathrm{L}} \mathrm{L}^{-1}\right)$ & $\mathrm{K}_{\mathrm{i}}\left(\mathrm{mol} \cdot \mathrm{L}^{-1}\right)$ & $\mathrm{n}$ & $\mathrm{R}^{2}$ \\
\hline 30 & 0,0163 & 0,969 & 0,698 & 19,24 & 0,963 \\
40 & 0,0298 & 1,473 & 0,777 & 14,76 & 0,998 \\
50 & 0,0155 & 0,702 & 0,741 & 17,34 & 0,919 \\
\hline
\end{tabular}

A temperatura influencia no valor do parâmetro $V_{m}$. Quando o valor da temperatura é modificado de 30 para $40^{\circ} \mathrm{m}$, ocorre um aumento no valor do parâmetro de 0,0163 para $0,0298 \mathrm{~mol} . \mathrm{L}^{-1} / \mathrm{minuto}$, ou seja, ele aumenta em quase duas vezes seu valor. Além disso, quando a temperatura é modificada para $50{ }^{\circ} \mathrm{C}$, é obtido um valor de $0,0155 \mathrm{~mol} . \mathrm{L}^{-1} / \mathrm{minuto}$ Esse comportamento foi observado também para a velocidade máxima atingida pela reação, apresentando valores de 0,0067 , 0,0092 e $0,0080 \mathrm{~mol} . \mathrm{L}^{-1} / \mathrm{minuto}$ para as temperaturas de 30,40 e $50{ }^{\circ} \mathrm{C}$ respectivamente. Dessa forma, é possível observar que o efeito da temperatura sobre a velocidade máxima alcançada pela reação em uma determinada concentração de substrato pode ser representada matematicamente por esse parâmetro.
Com relação à $K_{\mathrm{s}}$, pode-se afirmar que ele possui relação direta com o parâmetro $V_{m}$, ou seja, quando o valor da velocidade máxima atingida pela reação aumenta, o valor de Ks acompanha esse aumento.

Para $K_{i}$, foi encontrado um valor médio de 0,738 \pm 0,032 mol. $\mathrm{L}^{-1}$. Como o desvio médio se encontra por volta de apenas $4 \%$, pode-se afirmar que ele assume um valor constante para todos os valores de temperatura. Matematicamente é próximo dos valores de concentração inicial de substrato a partir do qual se observa uma queda na velocidade inicial da reação devido à inibição pelo substrato.

O acompanhamento da reação de forma qualitativa se deu através da análise de espectros de infravermelho. O gráfico da Figura 7 foi obtido em um instante intermediário do curso da reação.

Através do espectro ilustrado é possível observar que a reação se processa através do consumo de ácido octanoico, representado pela transmitância por volta de $1710 \mathrm{~cm}^{-1}$ e o surgimento do octanoato de $n$-pentila representado pela transmitância na região de $1736 \mathrm{~cm}^{-1}$ (NAKANISHI; SOLOMON, 1977; SILVERSTEIN; WEBSTER, 1997). Isso demonstra que a variação do consumo de base durante a titulação volumétrica é causada devido à conversão do ácido em éster e não a qualquer outro fator inerente ao processo. 


\section{Conclusões}

Tendo em vista os resultados discutidos, pode-se concluir que a enzima Lipozyme TL IM apresenta inibição pelos substratos a partir de concentrações por volta de $0,65 \mathrm{~mol} . \mathrm{L}^{-1}$, para valores de temperatura iguais a 30,40 e $50^{\circ} \mathrm{C}$. O modelo matemático clássico não é eficiente para descrever o comportamento da reação tratada neste trabalho, entretanto o modelo de Wu et al. (1998) adaptou-se bem aos dados experimentais.

\section{Agradecimentos}

À UNISUL, UFSC e Novozymes.

\section{Referências bibliográficas}

ABBAS, H.; COMEAU, L. Aroma synthesis by immobilized lípase from Mucor sp. Enzyme and Microbial Technology, v. 32, n. 5, p. 589-585, 2003.

CASTRO, H. F.; PAULA, A. V.; BARBOZA, J. S. estudo da influência do solvente, carboidrato e ácido graxo na síntese enzimática de ésteres de açúcares. Química Nova, v. 28, n. 5, p. 792-796, 2005.

CHANG, S. et al. Optimal lipase-catalyzed formation of hexyl laurate. Green Chemistry, v. 7, n. 7, p. 547-551, 2005.

CHANG, S. W.; SHAW, J. F.; SHIEH, C. J. Optimization of enzymatically prepared hexyl butyrate by Lipozyme IM-77. Food Technology and Biotechnology, v. 41, n. 3, p. 237-242, 2003.

CONNORS, K. A. Chemical kinetics: the study of reactions rates in solution. New York: VCH, 1990.

COSTA NETO, P. R. Obtenção de ésteres alquílicos (Biodiesel) por via enzimática a partir do óleo de soja. 2002. 118 f. Dissertação (Doutorado em Química)-Universidade Federal de Santa Catarina - UFSC, Florianópolis, 2002.

COSTA, P. et al. Substâncias carboniladas e derivados. Porto Alegre: Bookman, 2003.

DALLA-VECHIA, R.; NASCIMENTO, M. G.; SOLDI, V. Aplicações sintéticas de lipases imobilizadas em polímeros. Química Nova, v. 27, n. 4, p. 623-630, 2004.

DIAS, S. F. et al. Production of ethyl butyrate by Candida rugosa lipase immobilized in polyurethane. Biocatalysis and Biotransformation, v. 5, n. 1, p. 21-34, 1991.

FABER, K. Biotransformations in organic chemistry. Berlin: Springer-Verlag, 2000.

FERREIRA-DIAS, S.; FONSECA, M. M. R. The effect of substrate hydrophobicity on the kinetic behaviour of immobilized candida rugosa lipase. Biocatalysis and Biotransformation, v. 13, n. 2, p. 99-110, 1995.

GABELAN, A. Bioprocess production of flavor, fragance, and color ingredientes. New York: Wiley, 1994.

GANDHI, N. N. Applications of lipase. Journal of the American Oil Chemists' Society, v. 74, n. 6, p. 621-634, 1997.

JESUS, P. C.; SILVA, J. E. S. Evaluation of the Catalytic Activity of Lípases Immobilized on Chrysotile for Esterification. Anais da Academia Brasileira de Ciências, n. 75, 2003.

JOÃO, J. J.; ZANELLA, C. R. Utilização de enzimas em meio orgânico. Biotecnologia Ciência \& Desenvolvimento, v. 32, n. 16, p. 32-36, 2000.

MACLEOD, A.; SNYDER, C. H. Volatile components of two cultivars of mango from Florida. Journal Agricultural and Food Chemistry, v. 33, p. 380, 1985.

MOSER, A. Bioprocess technology: kinetics and reactors. New York: Spinger-Verlag, 1988.

NAKANISHI, K.; SOLOMON, P. H. Infrared absorption spectroscopy. $2^{\text {nd }}$ ed. San Francisco: Holden-Day, 1977.

OLIVEIRA, D. et al. Influência das variáveis de processo na alcoólise enzimática de óleo de mamona. Ciência e Tecnologia de Alimentos, v. 24 , n. 2, p. 178-182, 2004.

REHM, H. et al. Biotechnology: enzymes, biomass, food and feed. New York: VCH, 1995.

ROBERTS, J. D.; CASERIO, M. C. Basic principles of organic chemistry. $2^{\text {nd }}$ ed. California: W. A. Benjamin, 1977.

SCHIMIDELL, W. et al. Biotecnologia industrial: engenharia bioquímica. São Paulo: Edgard Blücher, 2001.

SCHMID, R.; VERGER, R. Lipases: interfacial enzymes with attractive applications. Angewandte Chemie International, v. 37, n. 12, p. 1608-1633, 1998.

ŞEKEROĞLU, G.; FADILOĞLU, S.; İBANOĞLU, E. Production and characterization of isopropyl laurate using immobilized lipase. Turkish Journal of Engineering \& Environmental Sciences, v. 28, n. 4, p. 241-248, 2004.

SHULER, M. L.; KERGI, F. Bioprocess engineering. New Jersey: Prentice Hall, 1992.

SILVERSTEIN, R. M.; WEBSTER, F. X. Spectrometric identification of organic compounds. New York: John Wiley, 1997.

VIEIRA, A. P. A.; SILVA, M. A. P.; LANGONE, M. A. P. Biodiesel production via esterification reactions catalyzed by lipase. Latin American Applied Research, v. 36, n. 4, p. 283-288, 2006.

WU, Y. C. et al. Treatment of leachate from solid waste landfill site using a two-stage anaerobic filter. Biotechnology and Bioengineering, v. 31, p. 257-266, 1998. 